\section{Atenção primária integral e sistemas segmentados de saúde na América do Sul}

\author{
Comprehensive primary care and segmented \\ health systems in South America
}

\author{
Atención primaria integral y sistemas \\ segmentados de salud en Suramérica
}

Ligia Giovanella 1

Patty Fidelis de Almeida 2

doi: 10.1590/0102-311X00118816

\section{Resumo}

O artigo analisa o processo recente de reformas da atenção primária à saúde nos países da América do Sul, discutindo alcance e desafios para a constituição de uma atenção primária integral nos sistemas de saúde da região. Tendo como fontes de informação estudos de caso realizados nos 12 países, toma, como eixos de análise, componentes estratégicos da concepção e implementação da atenção primária à saúde: abordagens nas politicas nacionais, características do financiamento, organização e prestação e a força de trabalho em atenção primária à saúde. A análise transversal em perspectiva comparada oferece um panorama da atenção primária à saúde nos países da região e destaca convergências e assimetrias. Observa-se, como traço comum, o resgate da concepção ampliada de atenção primária à saúde com componentes familiar e comunitário, base territorial, equipe multidisciplinar, incorporação de agentes comunitários de saúde e participação social. Na implementação, heterogeneidades nos avanços e contradições nos modelos se destacam. A insuficiente oferta de médicos, dificuldades para provisão e fixação em zonas remotas e periféricas, bem como na própria atenção primária à saúde, precariedade dos vínculos e ausência de carreira são problemas comuns, com iniciativas recentes de intervenção estatal no direcionamento da força de trabalho para o sistema público. A segmentação da oferta de atenção primária à saúde converge com a segmentação da proteção social em saúde nos diversos países seja pela manutenção dos seguros sociais, dos seguros seletivos e focalizados, pela cobertura por seguros privados de saúde ou pela manutenção de populações excluídas do direito à saúde. Argumenta-se que a implementação da atenção primária integral está condicionada às modalidades de proteção social em saúde vigentes.

\section{Correspondência}

P. F. Almeida

Instituto de Saúde Coletiva, Universidade Federal Fluminense.

Rua Marquês do Paraná 303, $3^{\circ}$ andar, Niterói, RJ

24030-2100, Brasil.

pattyfidelis@id.uff.br

1 Escola Nacional de Saúde Pública Sergio Arouca, Fundação Oswaldo Cruz, Rio de Janeiro, Brasil.

2 Instituto de Saúde Coletiva, Universidade Federal Fluminense, Niterói, Brasil. 


\section{Introdução}

O presente artigo analisa o processo recente de reformas da atenção primária à saúde nos países da América do Sul, buscando discutir o alcance e os desafios para a constituição de uma atenção primária integral nos sistemas de saúde da região.

$\mathrm{Na}$ América do Sul, a partir da primeira década do século XXI, com os processos de redemocratização e assunção de governos de centro-esquerda e esquerda, mais comprometidos com a justiça social, ganharam destaque, no contexto das reformas dos sistemas de saúde, processos de revitalização da atenção primária à saúde, em uma abordagem abrangente, reafirmando princípios da Declaração de Alma-Ata. Não obstante, na maior parte dos países, a implementação dessas reformas enfrenta importantes desafios originados na herança de modelos de atenção primária à saúde focalizados com redução do papel prestador do Estado, seletividade nos serviços e na eleição de seus usuários, das reformas pró-mercado dos sistemas de proteção social da década anterior, do contexto de segmentação dos sistemas de saúde e de profundas iniquidades sociais $1,2,3$.

Uma característica marcante dos sistemas de saúde na América do Sul é a segmentação da cobertura decorrente das modalidades de proteção social prevalentes na região 4 com estratificação de grupos cobertos, dada a heterogeneidade e elevada informalidade no mercado de trabalho e persistente exclusão social 5 . Nos anos 1980, com os programas de ajuste estrutural, ganharam proeminência, na agenda social latino-americana, os temas das redes sociais de proteção mínima aos pobres, prestação social por organizações não governamentais (ONGs) e setor privado, e os Programas de Transferência de Renda Condicionada, com repasse de recursos financeiros para grupos populacionais de baixa renda mediante comprovação de condicionalidades estabelecidas 6 .

Na saúde, essas premissas resultaram em ressegmentação com subsídios à demanda por meio da criação de seguros destinados à cobertura de grupos populacionais específicos, como o materno-infantil ou populações em extrema pobreza, contemplando pacotes mínimos de serviços característicos da atenção primária à saúde seletiva. Ao mesmo tempo, foi introduzida a cobrança nos serviços públicos de saúde com obrigatoriedade de copagamentos, inclusive para a população de baixa renda 7,8 .

A agenda governamental, a partir de meados dos anos 2000, incorporou os desafios de construir instituições democráticas e promover a inclusão social em contexto de intensas disparidades sociais, sendo que o combate à pobreza tornou-se prioridade. Variados programas de assistência social, incluindo aposentadorias não contributivas e transferências condicionadas de renda, quebrando a relação entre proteção social e mercado de trabalho, foram implementados ou expandidos ${ }^{9}$. Na saúde, entrou, na agenda governamental, a perspectiva da universalização de sistemas públicos de saúde com base a novos modelos assistenciais em atenção primária à saúde 10 .

Internacionalmente, reconhecem-se benefícios de sistemas de saúde sustentados por atenção primária à saúde de qualidade 11. São clássicos os estudos de Starfield et al. 12 demonstrando efeitos positivos nos resultados em saúde, acesso, equidade e eficiência dos sistemas de saúde. Atualmente, o fortalecimento da atenção primária é considerado uma das estratégias mais efetivas para responder as mudanças no perfil de morbimortalidade 11 .

Não obstante certa unanimidade quanto aos benefícios da atenção primária à saúde e reafirmação de princípios de Alma-Ata, predominam imprecisões e contradições conceituais com diversas abordagens em disputa. A própria permanência da prioridade da atenção primária à saúde por longo período e sob discursos díspares pode ser decorrência dessa imprecisão conceitual que permite abarcar iniciativas por vezes contrapostas: "uma receita para todas as estações” 13,14. Essas imprecisões decorrem das diversas influências e antecedentes imediatos e remotos de Alma-Ata: no modelo epidemiológico militar vetorial das campanhas de saúde pública; nos programas integrais e de educação para a saúde com pessoal comunitário; nos programas de medicina comunitária estadunidenses para aliviar tensões sociais; na perspectiva religiosa missional das experiências de saúde comunitária do Conselho Mundial de Igrejas; nas iniciativas de extensão do acesso aos serviços de saúde e aos benefícios científicos a toda população nos processos de descolonização e democratização dos então denominados países do terceiro mundo 13,14 .

Imediatamente pós Alma-Ata, em contexto de crise econômica e assunção de governos conservadores nos países centrais, seus ideais foram simplificados em uma cesta de serviços "custo-efetivos" 
para pobres, difundindo-se uma abordagem seletiva, incentivada por organismos internacionais. Uma concepção que Mario Testa 15 alcunhou de "primitiva", medicina pobre para pobres.

No presente artigo, a análise da atenção primária à saúde alinha-se à tradição da medicina social latino-americana que, com base na Declaração de Alma-Ata, desenvolveu uma abordagem de atenção primária integral (em contraposição a uma atenção primitiva) com componentes de: garantia de acesso universal a cuidados de saúde de qualidade, primeiro ponto de contato de uma rede integral de atenção à saúde; a indissociabilidade entre saúde e desenvolvimento econômico-social, o que implica na cooperação de outros setores para enfrentar determinantes sociais e promover a saúde; e de participação social para gerar autonomia e ampliar direitos sociais 3 . Essa abordagem de atenção primária à saúde integral, ainda que não plenamente operacionalizada, conforma o referencial normativo da análise realizada neste artigo.

Por meio da análise transversal de componentes e características da implementação da atenção primária à saúde nos países da América do Sul, argumenta-se que, em sistemas de proteção social à saúde segmentados, a fragmentação, a seletividade e a estratificação, inerentes ao modelo de proteção, obstaculizam a implementação de atenção primária integral, mesmo em contextos políticos favoráveis com governos de esquerda/centro-esquerda que tenham, como objetivo, a construção de sistemas universais.

\section{Metodologia}

As análises realizadas neste artigo tomam, como base, parte dos resultados do Mapeo de los Modelos de Atención Primaria de Salud en los Países de América del Sur, realizado pelo Instituto Sul-Americano de Governo em Saúde (Isags), organismo internacional do Conselho de Saúde Sul-Americano, da União das Nações Sul-americanas (Unasul). Para o mapeamento, foram realizados estudos de caso nos 12 países com base a uma matriz metodológica comum, tendo, como fontes de informação: revisão de literatura, análise documental, visitas a Ministérios da Saúde e serviços de atenção primária à saúde selecionados em cada país, entrevistas com informantes-chave governamentais e representantes de organizações comunitárias, no período de novembro de 2013 a abril de 2014. No conjunto dos países, foram entrevistados 129 gestores do nível federal ou provincial responsáveis pela atenção primária à saúde, 53 técnicos do nível local, 10 representantes de ONGs, usuários e lideranças comunitárias, e outros 14 informantes-chave (pesquisadores, ex-gestores ou autoridades nacionais) que participaram dos processos de reforma da atenção primária à saúde. Foram visitadas 57 unidades básicas de saúde (UBS) em municípios indicados, em geral, por gestores dos Ministérios da Saúde de cada país, identificadas como experiências exitosas na implementação dos novos modelos em atenção primária à saúde. O estudo abarcou a última década (período que vai de meados dos anos 2000 até 2014). A metodologia completa de realização do mapeamento e as informações coletadas organizadas em estudos de caso de cada país estão disponíveis na página de Internet do Isagas (http://www.isags-unasul.org/biblioteca. php?lg=2\&cat=7\&pag=9, acessado em 06/Abr/2016).

No presente artigo, tomam-se, como eixos de análise, componentes estratégicos das concepções e implementação da atenção primária à saúde: abordagens nas políticas nacionais; características do financiamento, organização e prestação; e força de trabalho em atenção primária à saúde. Para cada componente, foram selecionados dados e informações correspondentes dos 12 países, sintetizados em tabelas, e foi realizada análise transversal em perspectiva comparada, destacando convergências, similaridades e assimetrias entre os países. Os resultados buscam oferecer um panorama da atenção primária à saúde nos países da região, fugindo ao escopo do artigo a análise dos processos políticos e sociais específicos em cada país, que ademais apresentam características demográficas, econômicas e sociais muito distintas, como se pode depreender da apresentação de indicadores selecionados na Tabela 1. 
Tabela 1

Indicadores demográficos, econômicos e sociais selecionados. Países da América do Sul.

\begin{tabular}{|c|c|c|c|c|c|c|c|c|}
\hline País & $\begin{array}{l}\text { População em } \\
\text { milhões } 2015 \text { * }\end{array}$ & $\begin{array}{c}\text { PIB per } \\
\text { capita } \\
\text { (2013 ppp } \\
\text { US\$) * }\end{array}$ & $\begin{array}{c}\text { Razão } \\
\text { de renda } \\
20 \% \text { mais } \\
\text { ricos/20\% } \\
\text { mais pobres } \\
(2011-2013) \text { * }\end{array}$ & $\begin{array}{c}\text { Gasto em } \\
\text { saúde } \\
\text { per capita } \\
\text { (2014 US\$) }\end{array}$ & $\begin{array}{l}\text { \% gasto } \\
\text { público em } \\
\text { saúde } \\
\text { (\% gasto } \\
\text { total em } \\
\text { saúde, 2014) }\end{array}$ & $\begin{array}{c}\text { Gasto } \\
\text { público em } \\
\text { saúde como } \\
\% \text { do PIB } \\
(2010) * *\end{array}$ & $\begin{array}{c}\text { Taxa de } \\
\text { mortalidade } \\
\text { infantil } \\
(2015)\end{array}$ & $\begin{array}{c}\text { Taxa de } \\
\text { mortalidade } \\
\text { materna (2015) }\end{array}$ \\
\hline Argentina & 42,2 & - & 10,6 & 605 & 55,4 & 5,9 & 11 & 52 \\
\hline Bolívia & 11,0 & 5.750 & 15,2 & 209 & 72,1 & 4,0 & 31 & 206 \\
\hline Brasil & 203,7 & 14.750 & 16,9 & 947 & 46,0 & 4,0 & 15 & 44 \\
\hline Chile & 17,9 & 21.060 & 12,6 & 1.137 & 49,5 & 3,7 & 7 & 22 \\
\hline Colômbia & 49,5 & 11.960 & 17,5 & 569 & 75,1 & 5,2 & 14 & 64 \\
\hline Equador & 16,2 & 10.720 & 12,0 & 579 & 49,2 & 3,9 & 18 & 64 \\
\hline Guiana & 0,8 & 6.610 & - & 222 & 59,4 & 3,3 & 32 & 229 \\
\hline Paraguai & 7,0 & 7.670 & 13,0 & 464 & 45,9 & 4,3 & 18 & 132 \\
\hline Peru & 31,2 & 11.160 & 11,9 & 359 & 60,6 & 3,0 & 13 & 68 \\
\hline Suriname & 0,5 & 15.960 & - & 589 & 51,7 & 2,7 & 19 & 155 \\
\hline Uruguai & 3,4 & 18.940 & 9,0 & 1.442 & 71,2 & 5,9 & 9 & 15 \\
\hline Venezuela & 31,3 & 17.900 & - & 873 & 29,3 & 2,1 & 13 & 95 \\
\hline
\end{tabular}

PIB: Produto Interno Bruto.

Fontes: World Bank 30; * Organización Panamericana de la Salud 31; ** Organización Panamericana de la Salud 32.

\section{Resultados}

\section{Abordagens de atenção primária à saúde nas políticas nacionais de saúde}

Observa-se, para o conjunto das políticas nacionais de saúde dos países da América Latina, menção a processos de reforma da atenção primária à saúde, cujo eixo central é a oferta de atenção integral com garantia de ações preventivas, promocionais e assistenciais (Tabela 2). Sete países explicitam a atenção primária à saúde como a base de um modelo universal em saúde. Documentos oficiais expressam uma concepção de atenção primária à saúde inspirada pelos princípios da Declaração de Alma-Ata, em que pese a continuidade da oferta de pacotes para grupos específicos como nos casos da Argentina, Bolívia, Colômbia e Peru, e a permanência de um sistema de proteção social em saúde do tipo segmentado, com manutenção dos seguros sociais ou a criação de novos seguros focalizados, em passado recente. Bolívia, Equador e Venezuela trazem, como novidade, a incorporação da dimensão da interculturalidade como elemento formal da atenção primária à saúde nas políticas nacionais de saúde, reconhecendo a expressividade das práticas e saberes em saúde dos povos originários (Tabela 2). A integração entre medicina tradicional e serviços de saúde está mais desenvolvida na Bolívia, com o reconhecimento de médicos tradicionais e parteiras como parte das equipes de saúde, em conformidade com a tradição ancestral dos povos andinos em relação à atenção obstétrica e à criança. Tanto a Bolívia quanto o Equador integraram a atenção obstétrica intercultural às políticas nacionais de saúde. A Venezuela apresenta processo mais marginal, sendo as ações interculturais restritas à população indígena Yanomami 16.

Em sinergia com os processos de reforma dos sistemas de saúde, novos modelos de atenção primária à saúde são propostos em quase todos os países da região. Apresentam, em comum, dois elementos: comunidade e família. Mesmo os países que não mencionam a definição de um novo modelo têm seu processo de reorganização da atenção primária à saúde a partir da conformação de equipes multiprofissionais, em geral, compostas por médicos, enfermeiros e auxiliares/técnicos de enfermagem. Em coerência à concepção abrangente de atenção primária à saúde e ao componente comunitário expresso 
Tabela 2

Características das abordagens de atenção primária à saúde nas políticas nacionais de saúde dos países da América do Sul.

\begin{tabular}{|c|c|c|c|c|c|c|c|}
\hline \multirow[t]{2}{*}{$\begin{array}{l}\text { País (ano } \\
\text { da política) }\end{array}$} & \multicolumn{3}{|c|}{$\begin{array}{c}\text { Concepção de atenção primária à saúde } \\
\text { expressa na política nacional }\end{array}$} & \multicolumn{4}{|c|}{ Componentes do modelo assistencial de atenção primária à saúde } \\
\hline & $\begin{array}{c}\text { Prioridade } \\
\text { para } \\
\text { atenção } \\
\text { primária à } \\
\text { saúde nas } \\
\text { políticas de } \\
\text { saúde }\end{array}$ & $\begin{array}{c}\text { Definição } \\
\text { de novo } \\
\text { modelo } \\
\text { assistencial } \\
\text { de atenção } \\
\text { primária à } \\
\text { saúde }\end{array}$ & $\begin{array}{l}\text { Atenção } \\
\text { primária } \\
\text { à saúde } \\
\text { como base } \\
\text { de um } \\
\text { sistema } \\
\text { universal } \\
\text { de saúde }\end{array}$ & $\begin{array}{l}\text { Equipe } \\
\text { multiprofissional }\end{array}$ & Territorialização & $\begin{array}{l}\text { Ênfase na } \\
\text { interculturalidade }\end{array}$ & $\begin{array}{l}\text { Participação } \\
\text { social }\end{array}$ \\
\hline $\begin{array}{l}\text { Argentina } \\
(2004)\end{array}$ & Sim & - & - & $\begin{array}{c}\text { Médico, enfermeiro, } \\
\text { auxiliar de } \\
\text { enfermagem, parteira, } \\
\text { agentes comunitários } \\
\text { (pagos ou voluntários), } \\
\text { odontólogo }\end{array}$ & $\begin{array}{l}\text { Sim, diferenciada } \\
\text { por província }\end{array}$ & Não & Informal \\
\hline $\begin{array}{l}\text { Bolívia } \\
\text { (2008) }\end{array}$ & Sim & $\begin{array}{c}\text { Programa } \\
\text { de Salud } \\
\text { Familiar } \\
\text { Comunitaria } \\
\text { Intercultural } \\
\text { (SAFCI) }\end{array}$ & Sim & $\begin{array}{l}\text { Centro de saúde: } \\
\text { médico, odontólogo, } \\
\text { auxiliar ou técnico de } \\
\text { enfermagem. Posto } \\
\text { de saúde: auxiliar ou } \\
\text { técnico de enfermagem. } \\
\text { Responsáveis populares } \\
\text { de saúde (voluntários) }\end{array}$ & $\begin{array}{l}\text { Sim, com } \\
\text { adscrição } \\
\text { incipiente }\end{array}$ & Sim & $\begin{array}{c}\text { Formal } \\
\text { nacional e } \\
\text { local }\end{array}$ \\
\hline $\begin{array}{l}\text { Brasil } \\
(2006 / 2011)\end{array}$ & Sim & $\begin{array}{l}\text { Estratégia } \\
\text { Saúde da } \\
\text { Família (ESF) }\end{array}$ & Sim & $\begin{array}{c}\text { Equipe de Saúde } \\
\text { da Família: médico, } \\
\text { enfermeiro, 1-2 } \\
\text { auxiliar/técnico de } \\
\text { enfermagem, } 5 \text { a } 6 \\
\text { agentes comunitário de } \\
\text { saúde (pagos). Equipes } \\
\text { de Saúde Bucal: } \\
\text { odontólogo, auxiliar ou } \\
\text { técnico em saúde bucal }\end{array}$ & $\begin{array}{c}\text { Sim, usuários } \\
\text { cadastrados por } \\
\text { equipe }\end{array}$ & Não & $\begin{array}{c}\text { Formal } \\
\text { nacional e } \\
\text { local }\end{array}$ \\
\hline $\begin{array}{l}\text { Chile } \\
(2005 / 2013)\end{array}$ & Sim & $\begin{array}{l}\text { Modelo de } \\
\text { Atencíon } \\
\text { Integral } \\
\text { de Salud } \\
\text { Familiar y } \\
\text { Comunitario }\end{array}$ & - & $\begin{array}{l}\text { Médico, enfermeiro, } \\
\text { matrona, assistente } \\
\text { social, assistente } \\
\text { administrativo. } \\
\text { Monitores voluntários } \\
\text { da comunidade }\end{array}$ & $\begin{array}{l}\text { Sim, usuários } \\
\text { adscritos por } \\
\text { equipe. Inscrição } \\
\text { realizada por } \\
\text { iniciativa pessoal }\end{array}$ & Não & Formal local \\
\hline
\end{tabular}

(continua) 
Tabela 2 (continuação)

\begin{tabular}{|c|c|c|c|c|c|c|c|}
\hline \multirow[t]{2}{*}{$\begin{array}{l}\text { País (ano } \\
\text { da política) }\end{array}$} & \multicolumn{3}{|c|}{$\begin{array}{l}\text { Concepção de atenção primária à saúde } \\
\text { expressa na política nacional }\end{array}$} & \multicolumn{4}{|c|}{ Componentes do modelo assistencial de atenção primária à saúde } \\
\hline & $\begin{array}{l}\text { Prioridade } \\
\text { para } \\
\text { atenção } \\
\text { primária à } \\
\text { saúde nas } \\
\text { políticas de } \\
\text { saúde }\end{array}$ & $\begin{array}{l}\text { Definição } \\
\text { de novo } \\
\text { modelo } \\
\text { assistenci } \\
\text { atenção } \\
\text { primária à } \\
\text { saúde }\end{array}$ & $\begin{array}{l}\text { Atenção } \\
\text { primária } \\
\text { à saúde } \\
\text { como base } \\
\text { de um } \\
\text { sistema } \\
\text { universal } \\
\text { de saúde }\end{array}$ & $\begin{array}{c}\text { Equipe } \\
\text { multiprofissional }\end{array}$ & Territorialização & $\begin{array}{c}\text { Ênfase na } \\
\text { interculturalidade }\end{array}$ & $\begin{array}{c}\text { Participação } \\
\text { social }\end{array}$ \\
\hline $\begin{array}{l}\text { Colômbia } \\
\text { (2011) }\end{array}$ & Sim & - & - & $\begin{array}{c}\text { Não há regra } \\
\text { nacional. Em geral, as } \\
\text { equipes básicas são } \\
\text { conformadas por: } \\
\text { médico, enfermeiro, } \\
\text { promotores/ } \\
\text { caminhantes (pagos ou } \\
\text { voluntários), auxiliares } \\
\text { e técnicos em saúde }\end{array}$ & $\begin{array}{l}\text { Sim, em alguns } \\
\text { modelos } \\
\text { municipais. Não } \\
\text { há diretrizes } \\
\text { nacionais sobre } \\
\text { adscrição } \\
\text { populacional }\end{array}$ & Não & Formal local \\
\hline $\begin{array}{l}\text { Equador } \\
(2008 / 2012)\end{array}$ & Sim & $\begin{array}{l}\text { Modelo de } \\
\text { Atención } \\
\text { Integral } \\
\text { en Salud } \\
\text { Familiar } \\
\text { Comunitario } \\
\text { e } \\
\text { Intercultural } \\
\text { (MAIS-FCI) }\end{array}$ & Sim & $\begin{array}{c}\text { Médico, enfermeiro, } \\
\text { técnico em atenção } \\
\text { primária à saúde (pago) }\end{array}$ & $\begin{array}{l}\text { Sim, por circuitos } \\
\text { e distritos } \\
\text { e adscrição } \\
\text { populacional } \\
\text { por unidade de } \\
\text { saúde }\end{array}$ & Sim & $\begin{array}{l}\text { Formal } \\
\text { nacional e } \\
\text { local }\end{array}$ \\
\hline $\begin{array}{l}\text { Guiana } \\
(2010 / 2013)\end{array}$ & Sim & - & Sim & $\begin{array}{l}\text { Centros de saúde } \\
\text { tipos } 1 \text { e 2: médico, } \\
\text { enfermeiro, parteira, } \\
\text { Medex, assistente de } \\
\text { laboratório, auxiliar de } \\
\text { farmácia, assistente } \\
\text { odontológico, assistente } \\
\text { de reabilitação, agente } \\
\text { comunitário de saúde } \\
\text { (pago) assistente de } \\
\text { saúde ambiental }\end{array}$ & Não & Não & $\begin{array}{l}\text { Formal } \\
\text { nacional e } \\
\text { local }\end{array}$ \\
\hline $\begin{array}{l}\text { Paraguai } \\
\text { (2008) }\end{array}$ & Sim & $\begin{array}{l}\text { Unidade } \\
\text { de Salud } \\
\text { Familiar }\end{array}$ & Sim & $\begin{array}{l}\text { Médico, enfermeiro } \\
\text { ou enfermeiro } \\
\text { obstetra, auxiliar de } \\
\text { enfermagem e } 3 \text { a } 5 \\
\text { agentes comunitários } \\
\text { de saúde (pago). } \\
\text { Equipe odontológica: } \\
\text { odontólogo e técnico } \\
\text { odontológico }\end{array}$ & $\begin{array}{c}\text { Sim, usuários } \\
\text { adscritos por } \\
\text { equipes de saúde } \\
\text { da família }\end{array}$ & Não & Formal local \\
\hline
\end{tabular}

(continua) 
Tabela 2 (continuação)

\begin{tabular}{|c|c|c|c|c|c|c|c|}
\hline \multirow[t]{2}{*}{$\begin{array}{l}\text { País (ano } \\
\text { da política) }\end{array}$} & \multicolumn{3}{|c|}{$\begin{array}{c}\text { Concepção de atenção primária à saúde } \\
\text { expressa na política nacional }\end{array}$} & \multicolumn{4}{|c|}{ Componentes do modelo assistencial de atenção primária à saúde } \\
\hline & $\begin{array}{c}\text { Prioridade } \\
\text { para } \\
\text { atenção } \\
\text { primária à } \\
\text { saúde nas } \\
\text { políticas de } \\
\text { saúde }\end{array}$ & $\begin{array}{l}\text { Definição } \\
\text { de novo } \\
\text { modelo } \\
\text { assistenci } \\
\text { atenção } \\
\text { primária à } \\
\text { saúde }\end{array}$ & $\begin{array}{l}\text { Atenção } \\
\text { primária } \\
\text { à saúde } \\
\text { como base } \\
\text { de um } \\
\text { sistema } \\
\text { universal } \\
\text { de saúde }\end{array}$ & $\begin{array}{c}\text { Equipe } \\
\text { multiprofissional }\end{array}$ & Territorialização & $\begin{array}{l}\text { Ênfase na } \\
\text { interculturalidade }\end{array}$ & $\begin{array}{l}\text { Participação } \\
\text { social }\end{array}$ \\
\hline $\begin{array}{l}\text { Peru } \\
(2003 / 2011)\end{array}$ & Sim & $\begin{array}{l}\text { Modelo de } \\
\text { Atención } \\
\text { Integral } \\
\text { en Salud } \\
\text { Basado en } \\
\text { Familia y } \\
\text { Comunidad } \\
\text { (MAIS-BFC) }\end{array}$ & - & $\begin{array}{c}\text { Médico, enfermeiro, } \\
\text { enfermeiro obstetra, } \\
\text { técnico de enfermagem, } \\
\text { agentes comunitários } \\
\text { de saúde/promotores } \\
\text { (voluntários) }\end{array}$ & $\begin{array}{l}\text { Sim, usuários } \\
\text { adscritos } \\
\text { por área de } \\
\text { residência }\end{array}$ & Não & Formal local \\
\hline $\begin{array}{l}\text { Suriname } \\
(2012)\end{array}$ & Sim & - & - & $\begin{array}{c}\text { Médico geral, } \\
\text { enfermeiro, assistente } \\
\text { de saúde }\end{array}$ & Não & Não & Informal \\
\hline $\begin{array}{l}\text { Uruguai } \\
\text { (2007) }\end{array}$ & Sim & - & Sim & $\begin{array}{c}\text { Médico de família ou } \\
\text { generalista, enfermeiro, } \\
\text { parteira, pediatra e } \\
\text { ginecologista visitante } \\
\text { (equipe básica da } \\
\text { Administración de } \\
\text { los Servicios de Salud } \\
\text { del Estado - ASSE em } \\
\text { Montevidéu) }\end{array}$ & Não & Não & $\begin{array}{c}\text { Formal } \\
\text { nacional e } \\
\text { local }\end{array}$ \\
\hline $\begin{array}{l}\text { Venezuela } \\
(2004 / 2014)\end{array}$ & Sim & $\begin{array}{l}\text { Misión Barrio } \\
\text { Adentro }\end{array}$ & Sim & $\begin{array}{c}\text { Médico especialista em } \\
\text { medicina geral integral, } \\
\text { enfermeiro, agente } \\
\text { comunitário de atenção } \\
\text { primária em saúde } \\
\text { (pago) }\end{array}$ & $\begin{array}{l}\text { Sim, usuários } \\
\text { adscritos por } \\
\text { equipe no Barrio } \\
\text { Adentro }\end{array}$ & Sim & Formal local \\
\hline
\end{tabular}

Fonte: elaboração própria a partir de Giovanella 33. 
nas políticas nacionais, quase todos os países incorporaram, exceto o Uruguai, agentes comunitários de saúde como integrantes oficiais das equipes multiprofissionais, pagos ou voluntários (Tabela 2). A territorialização da atenção primária à saúde também está expressa nas políticas nacionais, sendo o modelo mais comum a adscrição dos usuários às equipes de saúde da família.

A participação social como elemento central dos processos de renovação da atenção primária à saúde, em geral, está institucionalizada na política nacional. Os países dividem-se quanto à abrangência da participação social. Bolívia, Brasil, Equador, Guiana e Uruguai com instâncias nacionais e locais, e os demais com representatividade local. Na Argentina e no Suriname, a participação social se processa em iniciativas informais, em geral de base comunitária, ou seja, não está institucionalizada pelas políticas nacionais de saúde.

\section{Financiamento, organização e prestação em atenção primária à saúde}

Em relação ao financiamento, observam-se diferentes arranjos entre os países da região que se relacionam aos modelos de atenção primária à saúde implementados, variando de transferências do nível central a programas específicos (Argentina, Equador, Guiana, Venezuela) às per capita segundo população municipal, como nos casos de Brasil e Chile. Diferente dos casos brasileiro e chileno, em países como Bolívia e Peru, há transferências per capita para os municípios, porém direcionadas aos seguros focalizados conforme número de segurados. Em outros países com maior grau de centralização, a execução financeira é realizada desde o nível central (Paraguai, Uruguai, Suriname). Diversos países aboliram o copagamento para os serviços de atenção primária à saúde. Colômbia, Bolívia, Chile e Uruguai mantêm copagamento para algumas classes de segurados ou tipos de serviços. Ademais, no Peru e na Bolívia, há copagamento nos serviços públicos para a população não segurada, e, no Suriname, para medicamentos.

A organização da atenção primária à saúde também é diversa entre os 12 países da América do Sul. Em conformidade com os mecanismos de transferência financeira, alguns países apresentam gestão e organização da atenção primária à saúde pelos respectivos Ministérios da Saúde, outros também por operadoras de seguros focalizados. No Suriname e na Guiana, há presença importante de ONGs (Tabela 3). Em geral, a atenção primária à saúde é prestada por centros e postos de saúde sob gestão municipal (Argentina, Brasil, Chile, Colômbia, Paraguai, Peru, Venezuela) e/ou estadual (Argentina, Bolívia, Colômbia, Equador, Uruguai).

Uma vez que uma concepção ampliada de atenção primária à saúde está definida nas políticas nacionais dos países da região, algumas características da prestação poderiam indicar seu grau de implementação como a definição da função de filtro, de tempos máximos de espera e cobertura populacional. Na maior parte dos casos, atenção primária à saúde é afirmada como porta de entrada preferencial e filtro para a atenção especializada. Contudo, não é possível concluir que o sistema se organiza a partir da atenção primária à saúde, uma vez que, em geral, a função de filtro está definida para os modelos implementados a partir dos processos de reforma, como é o caso do Programa Salud Familiar Comunitaria Intercultural (SAFCI), na Bolívia, Estratégia Saúde da Família (ESF), no Brasil, Modelo de Atención Integral en Salud Basado en Familia y Comunidad (MAIS-BFC), no Peru, e Misión Barrio Adentro, na Venezuela, cujas coberturas são variadas com permanência de diversos modelos de atenção primária à saúde concorrentes. A busca de maior integração e articulação da rede foi um dos principais pilares da reforma do sistema de saúde chileno a partir de dois eixos: garantias explícitas para toda a população e fortalecimento da autoridade sanitária nacional e regional. Nessa direção, a partir de 2002, com o processo de reforma da saúde, foi proposta a criação dos Consejos de Integración de Redes Asistenciales (CIRA), instância de caráter assessor e consultivo para articulação interinstitucional das redes assistenciais. O estabelecimento de tempos máximos de espera na atenção primária à saúde, com exceção do Uruguai, também não está definido. Nesse país, há controle das listas de espera para consultas em atenção primária à saúde e atenção especializada, que podem ser monitoradas e publicizadas por meio de sistemas de informação. As consultas em especialidades básicas devem ser realizadas em até 24 horas, e as especializadas, em até 30 dias. 
Tabela 3

Características do financiamento, organização e prestação em atenção primária à saúde nos países da América do Sul.

\begin{tabular}{|c|c|c|c|c|c|c|c|}
\hline País & $\begin{array}{l}\text { Mecanismos } \\
\text { de } \\
\text { transferências } \\
\text { financeiras } \\
\text { para atenção } \\
\text { primária à } \\
\text { saúde do } \\
\text { nível nacional } \\
\text { para esferas } \\
\text { subnacionais }\end{array}$ & $\begin{array}{l}\text { Copagamento } \\
\text { em atenção } \\
\text { primária à } \\
\text { saúde }\end{array}$ & $\begin{array}{c}\text { Principais } \\
\text { responsáveis } \\
\text { pela gestão/ } \\
\text { organização/ } \\
\text { prestação da } \\
\text { atenção primária } \\
\text { à saúde no nível } \\
\text { local }\end{array}$ & $\begin{array}{l}\text { Função de filtro } \\
\text { dos serviços } \\
\text { de atenção } \\
\text { primária à } \\
\text { saúde para } \\
\text { outros níveis }\end{array}$ & $\begin{array}{c}\text { Definição } \\
\text { de tempos } \\
\text { máximos de } \\
\text { espera para } \\
\text { consulta } \\
\text { atenção } \\
\text { primária à } \\
\text { saúde }\end{array}$ & $\begin{array}{l}\text { Estimativa } \\
\text { de cobertura } \\
\text { populacional } \\
\text { do novo } \\
\text { modelo }\end{array}$ & $\begin{array}{l}\text { Principais } \\
\text { segmentos de } \\
\text { cobertura de } \\
\text { serviços de } \\
\text { primeiro nível }\end{array}$ \\
\hline Argentina & $\begin{array}{c}\text { Por programas } \\
\text { específicos }\end{array}$ & Não & $\begin{array}{l}\text { Províncias e } \\
\text { municípios }\end{array}$ & $\begin{array}{l}\text { Diversificado } \\
\text { por províncias } \\
\text { ou municípios }\end{array}$ & Não & Não se aplica & $\begin{array}{c}\text { Seguros sociais: } \\
55 \% \\
\text { Sistema público: } \\
35 \%\end{array}$ \\
\hline Bolívia & $\begin{array}{c}\text { Per capita a } \\
\text { municípios } \\
\text { para segurados } \\
\text { de seguros } \\
\text { focalizados }\end{array}$ & $\begin{array}{c}\text { Pagamento } \\
\text { em serviços } \\
\text { públicos, } \\
\text { exceto para } \\
\text { os segurados } \\
\text { de seguros } \\
\text { focalizados }\end{array}$ & Departamentos & $\begin{array}{c}\text { Não } \\
\text { (fluxo definido } \\
\text { no Programa de } \\
\text { Salud Familiar } \\
\text { Comunitaria } \\
\text { Intercultural } \\
\text { (SAFCI) }\end{array}$ & Não & Sem data & $\begin{array}{c}\text { Seguros } \\
\text { focalizados: } 30 \% \\
\text { Seguros sociais: } \\
\text { 20\% Exclusão em } \\
\text { saúde: } 50 \%\end{array}$ \\
\hline Brasil & $\begin{array}{c}\text { Per capita a } \\
\text { municípios, } \\
\text { específica } \\
\text { para atenção } \\
\text { primária à } \\
\text { saúde }\end{array}$ & Não & Municípios & $\begin{array}{c}\text { Sim, } \\
\text { principalmente } \\
\text { na Estatégia } \\
\text { Saúde da } \\
\text { Família (ESF) }\end{array}$ & Não & $\begin{array}{c}\text { 60\% Equipe } \\
\text { de Saúde da } \\
\text { Família }\end{array}$ & $\begin{array}{c}\text { Sistema público: } \\
75 \%(100 \%) \\
\text { Seguros privados: } \\
25 \%\end{array}$ \\
\hline Chile & $\begin{array}{l}\text { Per capita a } \\
\text { municípios, } \\
\text { específica } \\
\text { para atenção } \\
\text { primária à } \\
\text { saúde }\end{array}$ & $\begin{array}{c}\text { Sim, para } \\
\text { segurados C } \\
\text { e D do Fondo } \\
\text { Nacional de } \\
\text { Salud (Fonasa). } \\
\text { Não, para os } \\
\text { grupos A e B }\end{array}$ & Municípios & Sim (Fonasa) & Não & $\begin{array}{c}\sim 40 \% \text { ( } 90 \% \text { dos } \\
\text { estratos A e B } \\
\text { de Fonasa) }\end{array}$ & $\begin{array}{l}\text { Seguro social: } \\
75 \% \\
\text { Seguros } \\
\text { privados: } 17 \% \\
\text { (Instituciones de } \\
\text { Salud Previsional } \\
\text { - Isapres - } \\
\text { obrigatório) }\end{array}$ \\
\hline Colômbia & $\begin{array}{c}\text { Transferências } \\
\text { somente para } \\
\text { o Plano de } \\
\text { Intervenciones } \\
\text { Colectivas (PIC) }\end{array}$ & $\begin{array}{l}\text { Sim, exceto para } \\
\text { as ações do PIC }\end{array}$ & $\begin{array}{l}\text { Municípios para } \\
\text { PIC. Seguradoras } \\
\text { (Empresas } \\
\text { Promotoras de } \\
\text { Salud - EPS) do } \\
\text { regime subsidiado } \\
\text { e contributivo } \\
\text { contratam serviços } \\
\text { públicos ou } \\
\text { privados }\end{array}$ & Sim & Não & Não se aplica & $\begin{array}{c}\text { Seguros } \\
\text { focalizados: } 48 \% \\
\text { (subsidiado) } \\
\text { Seguros } \\
\text { sociais: } 46 \% \\
\text { (contributivo) }\end{array}$ \\
\hline
\end{tabular}

(continua) 
Tabela 3 (continuação)

\begin{tabular}{|c|c|c|c|c|c|c|c|}
\hline País & $\begin{array}{l}\text { Mecanismos } \\
\text { de } \\
\text { transferências } \\
\text { financeiras } \\
\text { para atenção } \\
\text { primária à } \\
\text { saúde do } \\
\text { nível nacional } \\
\text { para esferas } \\
\text { subnacionais }\end{array}$ & $\begin{array}{l}\text { Copagamento } \\
\text { em atenção } \\
\text { primária à } \\
\text { saúde }\end{array}$ & $\begin{array}{c}\text { Principais } \\
\text { responsáveis } \\
\text { pela gestão/ } \\
\text { organização/ } \\
\text { prestação da } \\
\text { atenção primária } \\
\text { à saúde no nível } \\
\text { local }\end{array}$ & $\begin{array}{l}\text { Função de filtro } \\
\text { dos serviços } \\
\text { de atenção } \\
\text { primária à } \\
\text { saúde para } \\
\text { outros níveis }\end{array}$ & $\begin{array}{l}\text { Definição } \\
\text { de tempos } \\
\text { máximos de } \\
\text { espera para } \\
\text { consulta } \\
\text { atenção } \\
\text { primária à } \\
\text { saúde }\end{array}$ & $\begin{array}{c}\text { Estimativa } \\
\text { de cobertura } \\
\text { populacional } \\
\text { do novo } \\
\text { modelo }\end{array}$ & $\begin{array}{l}\text { Principais } \\
\text { segmentos de } \\
\text { cobertura de } \\
\text { serviços de } \\
\text { primeiro nível }\end{array}$ \\
\hline Equador & $\begin{array}{l}\text { Por orçamento } \\
\text { global e } \\
\text { programa } \\
\text { específico }\end{array}$ & Não & Províncias & Sim & Não & $70 \%$ & $\begin{array}{c}\text { Sistema público: } \\
72 \%(100 \%) \\
\text { Seguros sociais: } \\
28 \% \text { (acesso } \\
\text { universal à rede } \\
\text { do seguro social) }\end{array}$ \\
\hline Guiana & $\begin{array}{l}\text { Por programas } \\
\text { específicos }\end{array}$ & Não & $\begin{array}{l}\text { Serviços regionais } \\
\text { do Ministério da } \\
\text { Saúde; ONGs } \\
\text { internacionais }\end{array}$ & Incipiente & Não & Não se aplica & $\begin{array}{c}\text { Sistema público: } \\
100 \%\end{array}$ \\
\hline Paraguai & Não há & Não & $\begin{array}{l}\text { Ministério da } \\
\text { Saúde e municípios }\end{array}$ & $\begin{array}{c}\text { Sim, para as } \\
\text { Unidades de } \\
\text { Salud Familiar } \\
\text { (USF) }\end{array}$ & Não & $36 \%$ por USF & $\begin{array}{c}\text { Sistema público: } \\
\text { sem dados } \\
\text { Seguros sociais: } \\
16 \% \\
\text { Seguros privados: } \\
7 \% \\
\text { Exclusão: sem } \\
\text { dados }\end{array}$ \\
\hline Peru & $\begin{array}{l}\text { Per capita } \\
\text { para seguro } \\
\text { focalizado }\end{array}$ & $\begin{array}{c}\text { Sim, nos } \\
\text { serviços } \\
\text { públicos para } \\
\text { população não } \\
\text { assegurada }\end{array}$ & $\begin{array}{l}\text { Governos locais. } \\
\text { Seguradoras } \\
\text { (Instituciones } \\
\text { Administradoras } \\
\text { de Fondos de } \\
\text { Aseguramiento } \\
\text { en Salud - IAFAS) } \\
\text { que contratam } \\
\text { serviços públicos } \\
\text { ou privados }\end{array}$ & $\begin{array}{l}\text { Nos serviços } \\
\text { do Modelo } \\
\text { de Atención } \\
\text { Integral en } \\
\text { Salud Basado } \\
\text { en Familia y } \\
\text { Comunidad } \\
\text { (MAIS-BFC) }\end{array}$ & Não & $\begin{array}{c}17 \% \text { das } \\
\text { unidades de } \\
\text { primeiro nível } \\
\text { com MAIS-BFC }\end{array}$ & $\begin{array}{c}\text { Seguros } \\
\text { focalizados: } 39 \% \\
\text { Seguros sociais: } \\
21 \% \\
\text { Sem cobertura: } \\
66 \%\end{array}$ \\
\hline Suriname & Não há & $\begin{array}{c}\text { Sim, para } \\
\text { medicamentos. } \\
\text { Não, para } \\
\text { população } \\
\text { atendida pela } \\
\text { Missão Médica }\end{array}$ & $\begin{array}{l}\text { Ministério da } \\
\text { Saúde. } \\
\text { ONG: Missão } \\
\text { Médica }\end{array}$ & Não & Não & Não se aplica & $\begin{array}{c}\text { Seguros sociais: } \\
21 \% \text { Seguro } \\
\text { focalizado: } 24 \% \\
\text { Seguros privados: } \\
13 \% \\
\text { Sem cobertura: } \\
20 \%\end{array}$ \\
\hline
\end{tabular}

(continua) 
Tabela 3 (continuação)

\begin{tabular}{|c|c|c|c|c|c|c|c|}
\hline País & $\begin{array}{l}\text { Mecanismos } \\
\text { de } \\
\text { transferências } \\
\text { financeiras } \\
\text { para atenção } \\
\text { primária à } \\
\text { saúde do } \\
\text { nível nacional } \\
\text { para esferas } \\
\text { subnacionais }\end{array}$ & $\begin{array}{l}\text { Copagamento } \\
\text { em atenção } \\
\text { primária à } \\
\text { saúde }\end{array}$ & $\begin{array}{c}\text { Principais } \\
\text { responsáveis } \\
\text { pela gestão/ } \\
\text { organização/ } \\
\text { prestação da } \\
\text { atenção primária } \\
\text { à saúde no nível } \\
\text { local }\end{array}$ & $\begin{array}{l}\text { Função de filtro } \\
\text { dos serviços } \\
\text { de atenção } \\
\text { primária à } \\
\text { saúde para } \\
\text { outros níveis }\end{array}$ & $\begin{array}{c}\text { Definição } \\
\text { de tempos } \\
\text { máximos de } \\
\text { espera para } \\
\text { consulta } \\
\text { atenção } \\
\text { primária à } \\
\text { saúde }\end{array}$ & $\begin{array}{c}\text { Estimativa } \\
\text { de cobertura } \\
\text { populacional } \\
\text { do novo } \\
\text { modelo }\end{array}$ & $\begin{array}{c}\text { Principais } \\
\text { segmentos de } \\
\text { cobertura de } \\
\text { serviços de } \\
\text { primeiro nível }\end{array}$ \\
\hline Uruguai & Não há & $\begin{array}{l}\text { Sim, exceto nos } \\
\text { prestadores } \\
\text { públicos }\end{array}$ & $\begin{array}{l}\text { Administración de } \\
\text { los Servicios de } \\
\text { Salud del Estado } \\
\text { (ASSE), seguros } \\
\text { sociais: serviços } \\
\text { ambulatoriais } \\
\text { do setor privado } \\
\text { regulado }\end{array}$ & $\begin{array}{l}\text { Nos serviços } \\
\text { ASSE }\end{array}$ & Sim & Não se aplica & $\begin{array}{c}\text { Seguros sociais: } \\
60 \% \\
\text { Sistema público: } \\
30 \% \\
\text { Seguros privados: } \\
13 \%\end{array}$ \\
\hline Venezuela & $\begin{array}{l}\text { Por orçamento } \\
\text { global e } \\
\text { programa } \\
\text { específico }\end{array}$ & Não & $\begin{array}{c}\text { Ministério da } \\
\text { Saúde e municípios }\end{array}$ & $\begin{array}{l}\text { Nos serviços da } \\
\text { Misión Barrio } \\
\text { Adentro }\end{array}$ & Não & $\begin{array}{l}\sim 60 \% \text { Barrio } \\
\text { Adentro }\end{array}$ & $\begin{array}{c}\text { Sistema público: } \\
\text { 60\% (100\%) } \\
\text { Seguros sociais: } \\
\text { 39\% (acesso } \\
\text { universal à rede } \\
\text { do seguro social) }\end{array}$ \\
\hline
\end{tabular}

ONG: organização não governamental.

Fonte: elaboração própria a partir de Giovanella 33. Para cobertura por segmento, consultar também Giovanella et al. 4.

\section{Força de trabalho em atenção primária à saúde}

A disponibilidade, a formação e os vínculos dos profissionais da atenção primária à saúde para o sistema público de saúde representam um dos grandes desafios para a implementação dos novos modelos. Suas características são sumarizadas na Tabela 4. A insuficiência de médicos para atenção primária à saúde, observada na maior parte dos países, é representada pelo número total de médicos por mil habitantes. Ou seja, essa é uma estimativa geral do número de profissionais no país atuantes nos setores público e privado, em qualquer nível de atenção. Não foi possível conhecer estimativas de quantitativos de médicos de atenção primária à saúde para a maior parte dos países.

Permanece um mix de vínculos trabalhistas ao interior dos países, conformado por funcionários públicos, contratos temporários e bolsas, e apenas o Chile apresenta uma carreira para os profissionais da atenção primária à saúde. Não obstante, há consenso entre os gestores quanto às dificuldades de fixação, sobretudo em zonas remotas ou desfavorecidas. Como estratégia de enfrentamento desse problema, nove países mantêm cooperação com Cuba, principalmente para a provisão de médicos para a atenção primária à saúde. Outra estratégia para provisão é o fortalecimento de programas de pós-graduação, principalmente residências, em medicina de família e comunidade, o que é coerente aos modelos de atenção primária à saúde implementados a partir das reformas (Tabela 4). Na maior parte dos países, a regulação da profissão médica é realizada pelos Ministérios da Saúde, uma atribuição recente no caso do Equador, e, em parte, é autorregulada, o que confere autonomia aos conselhos e entidades de classe, como é o caso do Brasil. 
Tabela 4

Características da força de trabalho em atenção primária à saúde nos países da América do Sul.

\begin{tabular}{|c|c|c|c|c|c|c|c|}
\hline País & $\begin{array}{l}\text { Número de } \\
\text { médicos por } \\
\text { mil habitantes }\end{array}$ & $\begin{array}{l}\text { Vínculos } \\
\text { trabalhistas } \\
\text { na atenção } \\
\text { primária à } \\
\text { saúde }\end{array}$ & $\begin{array}{l}\text { Plano de } \\
\text { carreira } \\
\text { em } \\
\text { atenção } \\
\text { primária } \\
\text { à súde }\end{array}$ & $\begin{array}{l}\text { Políticas para } \\
\text { provimento } \\
\text { de médicos } \\
\text { em zonas } \\
\text { remotas e/ou } \\
\text { desfavorecidas }\end{array}$ & $\begin{array}{l}\text { Presença } \\
\text { de } \\
\text { médicos } \\
\text { cubanos }\end{array}$ & $\begin{array}{l}\text { Iniciativas recentes } \\
\text { de formação de } \\
\text { profissionais para } \\
\text { atenção primária à } \\
\text { saúde }\end{array}$ & $\begin{array}{l}\text { Regulação } \\
\text { do exercício } \\
\text { da profissão } \\
\text { médica }\end{array}$ \\
\hline Argentina & $3,9(2013)$ & $\begin{array}{c}\text { Contratos } \\
\text { renováveis por } \\
\text { avaliação de } \\
\text { desempenho } \\
\text { e temporários; } \\
\text { funcionários } \\
\text { públicos }\end{array}$ & Não & $\begin{array}{l}\text { Programa } \\
\text { Médicos } \\
\text { Comunitários }\end{array}$ & Não & $\begin{array}{l}\text { Pós-graduação em saúde } \\
\text { social e comunitária; } \\
\text { curso de saúde social e } \\
\text { comunitária (Programa } \\
\text { Médicos Comunitários) }\end{array}$ & $\begin{array}{c}\text { Diferenças por } \\
\text { províncias. } \\
\text { Em algumas, } \\
\text { é o Ministério } \\
\text { da Saúde; em } \\
\text { outras, é o } \\
\text { Colégio Médico } \\
\text { da Província }\end{array}$ \\
\hline Bolívia & $0,5(2014)$ & $\begin{array}{l}\text { Funcionários } \\
\text { públicos; } \\
\text { contratos } \\
\text { temporários }\end{array}$ & Não & $\begin{array}{l}\text { Residência } \\
\text { médica em } \\
\text { saúde familiar } \\
\text { e comunitária } \\
\text { intercultural }\end{array}$ & Sim & $\begin{array}{l}\text { Residência médica } \\
\text { em saúde familiar e } \\
\text { comunitária intercultural }\end{array}$ & $\begin{array}{l}\text { Ministério da } \\
\text { Saúde }\end{array}$ \\
\hline Brasil & $1,9(2013)$ & $\begin{array}{c}\text { Funcionários } \\
\text { públicos; } \\
\text { assalariados } \\
\text { setor privado; } \\
\text { contratos } \\
\text { temporários; } \\
\text { bolsas }\end{array}$ & Não & $\begin{array}{l}\text { Programa Mais } \\
\text { Médicos }\end{array}$ & Sim & $\begin{array}{c}\text { Residência em } \\
\text { medicina de família e } \\
\text { comunidade; residência } \\
\text { multiprofissional em } \\
\text { saúde da família; Pet- } \\
\text { Saúde e Pró-Saúde }\end{array}$ & Autorregulação \\
\hline Chile & $2,0(2013)$ & $\begin{array}{c}\text { Funcionários } \\
\text { públicos }\end{array}$ & Sim & $\begin{array}{l}\text { Incentivos } \\
\text { econômicos e } \\
\text { educativos }\end{array}$ & Sim & $\begin{array}{c}\text { Bolsas para especialização } \\
\text { em saúde familiar; } \\
\text { técnicos em saúde } \\
\text { familiar }\end{array}$ & Autorregulação \\
\hline Colômbia & $1,7(2011)$ & $\begin{array}{l}\text { Prestação } \\
\text { de serviços; } \\
\text { funcionários } \\
\text { públicos }\end{array}$ & Não & $\begin{array}{l}\text { Serviço civil } \\
\text { obrigatório }\end{array}$ & Não & $\begin{array}{c}\text { Programas para a } \\
\text { formação em medicina } \\
\text { familiar }\end{array}$ & $\begin{array}{l}\text { Ministério da } \\
\text { Saúde }\end{array}$ \\
\hline Equador & $1,7(2012)$ & $\begin{array}{l}\text { Funcionários } \\
\text { públicos; } \\
\text { contratos } \\
\text { temporários }\end{array}$ & Não & $\begin{array}{l}\text { Bolsas para } \\
\text { residência } \\
\text { e garantia } \\
\text { de contrato } \\
\text { ao finalizar; } \\
\text { obrigatoriedade } \\
\text { de um ano de } \\
\text { saúde rural }\end{array}$ & Sim & $\begin{array}{l}\text { Residência em medicina } \\
\text { familiar e comunitária; } \\
\text { Programa Ecuador } \\
\text { Saludable, Vuelvo Por } \\
\text { Ti de repatriação de } \\
\text { médicos; Técnico Em } \\
\text { Atenção Primária De } \\
\text { Saúde; Formação De } \\
\text { Médicos Na Escola } \\
\text { Latinoamericana de } \\
\text { Medicina de Cuba }\end{array}$ & $\begin{array}{l}\text { Ministério da } \\
\text { Saúde } \\
\text { (a partir de } \\
\text { 2010) }\end{array}$ \\
\hline
\end{tabular}

(continua) 
Tabela 4 (continuação)

\begin{tabular}{|c|c|c|c|c|c|c|c|}
\hline País & $\begin{array}{l}\text { Número de } \\
\text { médicos por } \\
\text { mil habitantes }\end{array}$ & $\begin{array}{l}\text { Vínculos } \\
\text { trabalhistas } \\
\text { na atenção } \\
\text { primária à } \\
\text { saúde }\end{array}$ & $\begin{array}{l}\text { Plano de } \\
\text { carreira } \\
\text { em } \\
\text { atenção } \\
\text { primária } \\
\text { à súde }\end{array}$ & $\begin{array}{l}\text { Políticas para } \\
\text { provimento } \\
\text { de médicos } \\
\text { em zonas } \\
\text { remotas e/ou } \\
\text { desfavorecidas }\end{array}$ & $\begin{array}{l}\text { Presença } \\
\text { de } \\
\text { médicos } \\
\text { cubanos }\end{array}$ & $\begin{array}{l}\text { Iniciativas recentes } \\
\text { de formação de } \\
\text { profissionais para } \\
\text { atenção primária à } \\
\text { saúde }\end{array}$ & $\begin{array}{l}\text { Regulação } \\
\text { do exercício } \\
\text { da profissão } \\
\text { médica }\end{array}$ \\
\hline Guiana & $0,9(2013)$ & $\begin{array}{c}\text { Funcionários } \\
\text { públicos }\end{array}$ & Não & $\begin{array}{l}\text { Medex e agentes } \\
\text { comunitários de } \\
\text { saúde }\end{array}$ & Sim & $\begin{array}{l}\text { Medex; Dentex; formação } \\
\text { na Escola Latinoamericana } \\
\text { de Medicina de Cuba }\end{array}$ & Autorregulação \\
\hline Paraguai & $1,3(2010)$ & $\begin{array}{l}\text { Funcionários } \\
\text { públicos; salários } \\
\text { mais bonificação; } \\
\text { contratos } \\
\text { renováveis por } \\
\text { avaliação de } \\
\text { desempenho }\end{array}$ & Não & $\begin{array}{l}\text { Incentivos } \\
\text { econômicos }\end{array}$ & Não & $\begin{array}{l}\text { Estágio rural na } \\
\text { graduação e } \\
\text { pós-graduação; residência } \\
\text { em medicina familiar; } \\
\text { pós-graduação em } \\
\text { medicina familiar }\end{array}$ & $\begin{array}{l}\text { Ministério da } \\
\text { Saúde }\end{array}$ \\
\hline Peru & $1,1(2012)$ & $\begin{array}{l}\text { Funcionários } \\
\text { públicos; } \\
\text { contrato } \\
\text { periódico de } \\
\text { administração } \\
\text { de serviços; } \\
\text { assalariado setor } \\
\text { privado }\end{array}$ & Não & $\begin{array}{l}\text { Programa de } \\
\text { Compensación e } \\
\text { Incentivos (PCl, } \\
\text { desde 2013) }\end{array}$ & Sim & $\begin{array}{l}\text { Programa nacional de } \\
\text { formação em saúde } \\
\text { familiar e comunitária }\end{array}$ & $\begin{array}{l}\text { Ministério da } \\
\text { Saúde }\end{array}$ \\
\hline Suriname & $1,0(2010)$ & $\begin{array}{c}\text { Contratos } \\
\text { por tempo } \\
\text { indeterminado }\end{array}$ & Não & $\begin{array}{l}\text { Assistentes de } \\
\text { saúde }\end{array}$ & Sim & $\begin{array}{l}\text { Formação de assistentes } \\
\text { de saúde; de enfermeiros } \\
\text { para atenção primária } \\
\text { à saúde; e em medicina } \\
\text { geral e em medicina de } \\
\text { família }\end{array}$ & $\begin{array}{l}\text { Ministério da } \\
\text { Saúde }\end{array}$ \\
\hline
\end{tabular}

(continua)

\section{Discussão}

A análise dos recentes processos de reforma da atenção primária à saúde nos 12 países da América do Sul permite traçar algumas sinergias, ou seja, eixos comuns trilhados pelos diversos países para o alcance de uma atenção primária integral, mas também a manutenção de desafios históricos que impedem avanços estruturais.

A partir dos anos 2000, processos de reforma setoriais foram observados em quase todos os países da América Latina. Todavia, os resultados são ainda inconclusos, marcados por contradições em relação ao conteúdo dos projetos, aos resultados alcançados e posicionamento frente ao contexto neoliberal dos anos de 1990 17. Conforme apontam Levino \& Carvalho 17, diante dos constrangimentos provocados pela redução do papel do Estado, as reformas sanitárias enfrentam problemas relacionados a financiamento, gestão do sistema, institucionalidade das políticas públicas, correlação de forças internas dos grupos políticos dominantes e do posicionamento da comunidade técnico-científica frente às estruturas de poder.

A realização do "mapeamento" explicita a heterogeneidade da atenção primária à saúde entre países e ao interior de cada país com experiências diversificadas, diferentes ênfases, passando por todo o 
Tabela 4 (continuação)

\begin{tabular}{|c|c|c|c|c|c|c|c|}
\hline País & $\begin{array}{l}\text { Número de } \\
\text { médicos por } \\
\text { mil habitantes }\end{array}$ & $\begin{array}{c}\text { Vínculos } \\
\text { trabalhistas } \\
\text { na atenção } \\
\text { primária à } \\
\text { saúde }\end{array}$ & $\begin{array}{l}\text { Plano de } \\
\text { carreira } \\
\text { em } \\
\text { atenção } \\
\text { primária } \\
\text { à súde }\end{array}$ & $\begin{array}{l}\text { Políticas para } \\
\text { provimento } \\
\text { de médicos } \\
\text { em zonas } \\
\text { remotas e/ou } \\
\text { desfavorecidas }\end{array}$ & $\begin{array}{c}\text { Presença } \\
\text { de } \\
\text { médicos } \\
\text { cubanos }\end{array}$ & $\begin{array}{l}\text { Iniciativas recentes } \\
\text { de formação de } \\
\text { profissionais para } \\
\text { atenção primária à } \\
\text { saúde }\end{array}$ & $\begin{array}{c}\text { Regulação } \\
\text { do exercício } \\
\text { da profissão } \\
\text { médica }\end{array}$ \\
\hline Uruguai & $4,5(2011)$ & $\begin{array}{l}\text { Administración } \\
\text { de los Servicios } \\
\text { de Salud del } \\
\text { Estado (ASSE): } \\
\text { contratos } \\
\text { temporários; } \\
\text { regime de } \\
\text { direito privado; } \\
\text { funcionários } \\
\text { públicos. } \\
\text { Instituições } \\
\text { de asistência } \\
\text { médica coletiva: } \\
\text { assalariados } \\
\text { setor privado; } \\
\text { prestação de } \\
\text { serviço }\end{array}$ & Não & $\begin{array}{l}\text { Incentivos } \\
\text { econômicos, } \\
\text { formação } \\
\text { descentralizada } \\
\text { e rotação de } \\
\text { residências no } \\
\text { interior }\end{array}$ & Sim & $\begin{array}{l}\text { Pós-graduação em } \\
\text { medicina familiar e } \\
\text { comunitária }\end{array}$ & $\begin{array}{c}\text { Ministério da } \\
\text { Saúde }\end{array}$ \\
\hline Venezuela & $3,8(2010)$ & $\begin{array}{c}\text { Funcionários } \\
\text { públicos; bolsas }\end{array}$ & Não & $\begin{array}{l}\text { Misión Barrio } \\
\text { Adentro, missão } \\
\text { médica cubana, } \\
\text { graduação de } \\
\text { medicina integral } \\
\text { comunitária }\end{array}$ & Sim & $\begin{array}{l}\text { Graduação em medicina } \\
\text { integral comunitária; } \\
\text { agentes comunitários } \\
\text { de atenção primária à } \\
\text { saúde; pós-graduação em } \\
\text { medicina geral integral }\end{array}$ & $\begin{array}{c}\text { Ministério da } \\
\text { Saúde }\end{array}$ \\
\hline
\end{tabular}

Fonte: elaboração própria a partir de Giovanella 33.

espectro de concepções e implementação. Observa-se, contudo, maior diversidade na implementação do que na formulação.

A análise dos casos aponta um traço comum - o resgate da concepção ampliada de Alma-Ata institucionalizada no âmbito das políticas nacionais. Em conformidade aos princípios de uma atenção primária à saúde integral, o componente familiar e comunitário, com base territorial, equipe multidisciplinar, com a incorporação de agentes comunitários de saúde e participação social são traços comuns aos processos de reforma nos países da América do Sul e, ao mesmo tempo, sua marca. Singular também é o reconhecimento, em alguns países, das práticas e saberes em saúde dos povos originários em uma lógica que, de alguma forma, questiona o paradigma hegemônico da biomedicina. Assim, no campo da formulação da política, têm-se, certamente, princípios e diretrizes que acenam para uma atenção primária integral na maior parte dos países, em um claro processo de renovação.

A análise transversal chama a atenção também para um processo de difusão de políticas na região, com formulações similares e uso de termos idênticos nos documentos e discursos dos dirigentes nacionais, oriundos não apenas da retórica opasiana 18, mas de processos de cooperação regional em novas bases, promovidos pela Unasul 19 e a Aliança Bolivariana para os Povos da Nossa América (Alba).

No campo da implementação da atenção primária à saúde, aqui analisado em seus componentes de financiamento, organização, prestação e políticas para força de trabalho, as heterogeneidades entre e ao interior dos países passam a ser o traço comum. 
A segmentação da proteção social em saúde também se expressa na atenção primária à saúde implementada. Congruente à persistência de modelos segmentados de sistemas de saúde nos países da região, mantém-se mecanismos de transferências financeiras para atenção primária à saúde por programas específicos e seguros focalizados em grande parte dos casos. Embora alguns países tenham abolido o copagamento a partir dos processos de reforma, esse ainda pode ser observado, especialmente nos casos em que a cobertura em saúde se processa por meio de afiliação a seguros.

Em relação à prestação dos serviços, a integração da rede assistencial, um dos atributos de uma atenção primária à saúde forte parece não consolidada e ainda pouco investigada nos países da região ${ }^{20}$. Mesmo que a maioria dos países tenha definido, nos novos modelos assistenciais, o papel de filtro pela atenção primária à saúde para a continuidade do cuidado, a conformação de redes assistenciais não se completou e permanecem problemas de acesso para serviços especializados. Ademais, nos países com seguros focalizados, a cobertura de serviços é seletiva com cesta restrita.

Por outro lado, o percentual de população coberta pelos novos modelos ainda é baixo em alguns países, e chama a atenção o importante número de países nos quais não foi possível apurar tal informação, mostrando a fragilidade e o alcance ainda restrito das reformas pró- atenção primária à saúde integral. A definição de tempos máximos de espera para a atenção primária à saúde, considerado um instrumento para garantia de acesso oportuno, como em países europeus 21 , também não foi verificado (exceto no Uruguai).

A efetiva integração da rede assistencial e garantia de cuidados integrais de qualidade é um componente da atenção primária integral nem sempre presente. Insuficiente integração é um problema reconhecido. Estudo sobre as modalidades de integração da atenção primária à saúde ao sistema de saúde na América Latina identificou três grupos: atenção primária seletiva no interior de programas materno-infantis, atenção primária à saúde como porta de entrada e eixo estruturante de um sistema público, e experiências municipais em sistemas baseados em seguros 2 .

Pode-se atribuir a insuficiente integração também a componentes do enfoque de atenção primária à saúde integral adotado. $\mathrm{O}$ enfoque da atenção primária promocional e preventivista, por vezes tido como uma concepção de atenção primária integral e de acordo com os princípios de Alma-Ata, desconsidera o acesso à atenção individual de qualidade como um dos determinantes da saúde. A perspectiva preventivista e promocional tem bases contraditórias, por um lado, predomínio do enfoque dos determinantes sociais e, por outro, corrobora iniciativas de reformas pró-mercado que propugnam a redução do papel do Estado como prestador e focalização de suas ações. Tejerina-Silva et al. 22 argumentam que essa acepção, com suas contradições, está também presente em países que implementaram novos modelos assistenciais, como Equador e Bolívia. Por um lado, são influenciados pela retórica da Organização Pan-Americana da Saúde (OPAS) que classifica a atenção primaria de países europeus, com sistemas universais, como apenas serviços de saúde de primeiro nível, e não reconhece os benefícios da medicina generalista, de família e comunidade, para a atenção individual. Por outro lado, essa seletividade decorre, em parte, de exigências de agências financeiras multilaterais que condicionam apoio a reformas com privatização e seletividade de serviços sociais, transferindo ao mercado a atribuição da atenção individual, especializada e hospitalar 23 .

A perspectiva promocional e preventivista da atenção primária à saúde amplia o espaço do setor privado para a atenção individual, e a propugnada atenção primária integral tende a restringir-se ao universalismo básico, versão renovada da atenção primária à saúde seletiva 22 . Tejerina-Silva et al. 22 alertam, contudo, que não se trata de negar a importância da determinação social dos processos saúde/enfermidade, mas reconhecer que o cuidado de saúde, em si, é um determinante social fundamental, e que a ação sobre os determinantes sociais, integrada à atenção generalista familiar, é a forma mais efetiva para a garantia do cuidado integral.

Em relação à força de trabalho em saúde, outro componente central para análise da abrangência dos processos de renovação, são observados problemas comuns como a insuficiente oferta de médicos e dificuldades para provisão e fixação desses profissionais em zonas remotas e periféricas, bem como na própria atenção primária à saúde. Não foi possível estimar o número de profissionais que atuam na área. A precariedade dos vínculos, associada à ausência de carreira para a atenção primária à saúde (exceto Chile), indica fraca intervenção estatal no direcionamento da força de trabalho para o sistema público de saúde. A consequência mais dramática para as populações, sobretudo aquelas residentes 
em zonas remotas ou desfavorecidas, é a ausência de profissionais médicos nessas regiões e a exclusão do acesso a serviços de saúde.

Ainda que, na maior parte dos países, o registro e a licença para o exercício da medicina tenham passado a ser responsabilidade dos Ministérios da Saúde, essa competência parece não ser suficiente para direcionar a formação e o exercício da profissão para as necessidades do sistema público de saúde. A assunção recente de maiores atribuições governamentais na regulação das profissões de saúde tem ocasionado conflitos sistemáticos com as corporações profissionais, com avanços limitados.

Essa incipiente regulação das relações de trabalho em atenção primária à saúde é traço comum associada a políticas de flexibilização do mercado de trabalho em geral, de novas formas de gestão na provisão de serviços sociais, incentivos à pluralidade de prestadores com participação de ONGs e prestadores privados, influenciados por iniciativas prévias de reformas gerenciais do Estado que propugnaram retirada da participação pública na provisão 6 sob a retórica de promover maior eficiência administrativa 24,25 .

Por outro lado, merecem destaque as inúmeras iniciativas nacionais de enfrentamento do problema da escassez de profissionais para a atenção primária à saúde na última década, por meio de estratégias de provisão emergencial, em especial com a participação de médicos cubanos, e também de redirecionamento das políticas de formação para as necessidades da atenção primária à saúde, cujos resultados poderão ser analisados em mais longo prazo. Venezuela se destaca pelo amplo programa de graduação em medicina integral comunitária que reduziu, de forma importante, a escassez de médicos no país 26 .

De toda forma, nos casos estudados, a segmentação da oferta de atenção primária à saúde converge com a segmentação da proteção social em saúde nos diversos países, seja pela manutenção dos seguros sociais, dos seguros seletivos e focalizados, pela cobertura por seguros privados de saúde ou persistência de populações excluídas do direito à saúde e de acesso aos serviços de saúde.

A implementação da atenção primária à saúde é condicionada pelo modelo de proteção social em saúde vigente. Vega-Romero \& Acosta-Ramírez 27 argumentam que, em países que têm, em comum, reformas setoriais orientadas ao mercado com base em asseguramento, seguindo as regras de separação e especialização das funções de reitoria, financiamento, asseguramento e prestação de serviços, com inclusão de agentes múltiplos públicos e privados, o subcomponente público está desenhado para a população sem capacidade de pagamento. Nesses modelos, as instituições administradoras de fundos de asseguramento determinam a organização de recursos e o modo de operação da atenção primária à saúde, distanciando a implementação das orientações da atenção primária à saúde renovada concebida em políticas nacionais. Ocorrem dicotomia e separação entre ações curativas individuais, contratadas pelas seguradoras a prestadores privados ou públicos, e ações de saúde pública, sob responsabilidade de governos territoriais, inclusive com financiamentos específicos, como nos casos da Colômbia e do Peru. Isto é, há fragmentação na prestação em atenção primária à saúde com diferentes prestadores encarregados para o cuidado individual e para ações coletivas de um mesmo grupo populacional 27. A criação de novos segmentos de cobertura com seguros públicos focalizados em populações em extrema pobreza, materno-infantil e/ou idosos, como nos casos da Bolívia e do Peru, impôs obstáculos adicionais para a universalização dos sistemas de saúde e para a garantia de cuidado integral.

Equador e Venezuela, ademais de tornarem o acesso aos serviços públicos de saúde gratuitos e implementar novos modelos assistenciais mais abrangentes em atenção primária, avançaram na universalização do sistema público à medida que universalizaram o acesso à rede de serviços de saúde própria dos seguros sociais. Por meio dessa medida, reduz-se a fragmentação e amplia-se o acesso à rede diversificada, ainda que não se alcance a unificação do sistema público de saúde, por resistências políticas de grupos de trabalhadores e servidores públicos cobertos 4,22. Simultaneamente, superposição de novas iniciativas à estrutura de gestão prévia com implementação paralela da rede de atenção primária à saúde e administração como, por exemplo, no caso do Barrio Adentro diretamente subordinada à presidência da nação, ampliam a fragmentação do sistema 16 .

Em suma, entre os países que, em suas políticas, estabelecem a atenção primária à saúde como base de um sistema universal de saúde e que buscam implementar um novo modelo assistencial com características que se aproximam do marco normativo para análise de atenção primária à saúde integral proposto neste artigo, Brasil, Equador e Venezuela destacam-se pela abrangência da implementação 
do novo modelo e pela perspectiva de construção de um sistema público universal de saúde (instituído, no Brasil, com o Sistema Único de Saúde e, em processo, no Equador e na Venezuela). Por sua vez, apesar da manutenção do desenho de cobertura estratificado, o Chile destaca-se pelos avanços na constituição de redes de atenção com integração entre atenção primária e especializada e pela regulação da qualidade e garantias de acesso à atenção integral.

A atenção primária à saúde com suas dubiedades conceituais segue também na pauta das agências multilaterais como estratégia para cobertura universal, que, nos países periféricos, tende a ser traduzida em universalismo básico ${ }^{18}$. Silveira et al. 18 , ao analisarem as proposições de atenção primária à saúde renovada da OPAS, tendo, como critérios, a população-alvo (universal ou focalizada), o escopo (abrangente ou restrito) e as relações público-privadas na organização dos serviços de atenção primária à saúde, identificam uma aproximação nos documentos da OPAS a uma concepção da proteção social de universalismo básico. Com acepção de serviços básicos universais fluida, a proposta seria adaptável à capacidade institucional de cada país, podendo compreender um escopo de serviços mais amplos ou restritos, tendo o Estado como regulador das relações entre setor público e privado.

Os desafios para implementação de atenção primária à saúde integral na América do Sul se alinham com aqueles da construção de sistemas públicos universais em nossa região, sendo condicionados pelas estratégias implementadas para a cobertura universal. Fleury et al. 25 reconhecem uma tendência geral de universalização de cobertura em saúde na América Latina, na última década, todavia, alertam que seguiu diferentes trajetórias: sistemas universais de saúde em contexto de restrição financeira; sistemas com desenho de cobertura estratificada; sistemas segmentados com cobertura focalizada; e novas abordagens multiculturais em saúde. Essas trajetórias indicam diferentes padrões de cidadania e de direito à saúde, cidadania residual com reforço à estratificação ou cidadania social de cidadãos portadores de direitos igualitários à saúde.

As contradições conceituais e na implementação da atenção primária à saúde na América do Sul aqui destacadas estão também relacionadas com as opções de políticas sociais dos governos progressistas na última década. Em contexto de intensas disparidades sociais, a promoção da inclusão social e o combate à pobreza tornaram-se prioridades, com ênfase em programas de transferência de renda, nem sempre acompanhados por ampliação de acesso a serviços públicos de qualidade. Para Lavinas 28 , na América Latina, a expansão da proteção social por meio de transferências monetárias, assegurando certo patamar de renda, sem simultaneamente promover a universalização da provisão de serviços sociais desmercantilizados, como saúde e educação, cuja premissa é dar melhor acesso em função da contingência, não da renda ou do status sócio-ocupacional, equivaleria a subsidiar a expansão do mercado privado desses serviços. A base da cidadania social plena é o acesso universal e incondicional a serviços públicos desmercadorizados. A autora argumenta que, na América Latina, ampliaram-se as transferências de renda, mas não a provisão de serviços públicos de saúde e educação, cuja universalização demanda recursos crescentes, tendo resultado na ampliação do mercado privado nesses setores. A transferência de renda condicionada, característica da cidadania residual, segundo a autora, busca resolver falhas de mercado: insere novos contingentes populacionais no mercado consumidor, facilitando algum acesso ao consumo individualizado de bens conforme capacidade de pagamento 28 .

Transformar o "direito em princípio" para o "direito na prática" enfrenta importantes constrangimentos políticos e econômicos 25 , acentuados no período recente. Ademais, prioridades na implementação das políticas sociais, com diferentes ênfases nos países da região, condicionam a implementação dos novos modelos assistenciais em atenção primaria à saúde e acentuam a tensão entre avançar na construção de redes integradas coordenadas pela atenção primária à saúde e implementar programas paralelos seletivos e focalizados.

\section{Considerações finais}

A atenção primária à saúde permanece na América Latina também como filosofia orientadora do agir político em saúde. Tejada de Rivero 29, coordenador da conferência de Alma-Ata, reafirma a atualidade da atenção primária à saúde, considerada como uma forma de cuidado integral de saúde que se aplica a todo o sistema de saúde, um bom uso da ciência e de tecnologias, uma ação multissetorial e 
transdisciplinar, um processo social e político eminentemente participativo na busca da equidade e da justiça social.

Em suma, permanecem tensões nas concepções e na implementação da atenção primária à saúde indissociáveis dos desafios da construção de sistemas públicos universais. Essas tensões tendem a se reatualizar nestes novos tempos críticos, políticos e econômicos, por que passam os países da América do Sul. Acompanhar esses processos no médio prazo e a consolidação ou não dos inegáveis avanços destacados neste artigo, em contexto de maior diversidade do panorama político social entre países da região, é tarefa para investigações futuras. As dubiedades e tensões na implementação da atenção primária à saúde aqui discutidas tendem a apontar para a permanência da sua vitalidade como "receita para todas as estações” 14. Mas, como argumentamos, atenção primária à saúde não é panaceia para todos os males - sem proteção social universal, não há atenção primária à saúde integral.

\section{Colaboradores}

L. Giovanella coordenou o estudo, participou da coleta, análise dos dados, concepção e redação final do artigo. P. F. Almeida participou da coleta, análise dos dados, concepção e redação final do artigo.

\section{Agradecimentos}

Agradecemos aos pesquisadores que realizaram o mapeamento da atenção primária à sáude na América do Sul - Gilberto Ríos Ferreira, Hedwig Goede, Herland Tejerina Silva, Naydú Acosta Ramírez, Román Vega Romero - e ao Instituto Sul-Americano de Governo em Saúde (Isags) da União das Nações Sul-Americanas (Unasul) pelo financiamento do projeto e disponibilização das informações. Ao Conselho Nacional de Desenvolvimento Científico e Tecnológico $(\mathrm{CNPq})$ pelas bolsas de produtividade concedida à L. Giovanella e de pós-doutorado júnior concedida à $\mathrm{P}$. F. Almeida. 


\section{Referências}

1. Soares L. Ajuste neoliberal e desajuste social na América Latina. Petrópolis: Editora Vozes; 2001.

2. Conill EM, Fausto MCR, Giovanella L. Contribuições da análise comparada para um marco abrangente na avaliação de sistemas orientados pela atenção primária na América Latina. Rev Bras Saúde Matern Infant 2010; 10 Suppl 1:S14-27.

3. Acosta Ramírez N, Pollard Ruiz J, Vega Romero R, Labonté R. Comprehensive primary health care in South America: contexts, achievements and policy implications. Cad Saúde Pública 2011; 27:1875-90.

4. Giovanella L, Ruiz G, Feo O, Tobar S, Faria M. Sistemas de salud en América del Sur. In: Instituto Sul-Americano de Governo em Saúde, organizador. Sistemas de salud en Suramérica: desafíos para la universalidad, la integralidad y la equidad. Rio de Janeiro: Instituto Sul-Americano de Governo em Saúde; 2012. p. 21-69.

5. Fleury S. Estados sem cidadãos. Rio de Janeiro: Editora Fiocruz; 1994.

6. Draibe S. Uma nova agenda social na América Latina? Pontos de partida para a análise comparada dos sistemas de proteção social e suas mudanças recentes. In: Sola L, Loureiro MR, organizadores. Democracia, mercado e estado. $\mathrm{O}$ B de BRICS. Rio de Janeiro: Editora FGV; 2011. p. 249-88.

7. Homedes N, Ugalde A. Las reformas de salud neoliberales en América Latina: una visión crítica a través de dos estudios de caso. Rev Panam Salud Pública 2005; 17:210-20.

8. Franco-Giraldo A, Palma M, Álvarez-Dardet C. Efecto del ajuste estructural sobre la situación de salud en América Latina y el Caribe, 1980-2000. Rev Panam Salud Pública 2006; 19:291-9.

9. Fleury S. The Welfare State in Latin America: reform, innovation and fatigue. Cad Saúde Pública 2017; 33 Suppl 2:e00058116.

10. Labonté R, Sanders D, Baum F, Schaay N, Packer C, Laplante D, et al. Aplicación, efectividad y contexto político de la atención primaria integral de salud: resultados preliminares de una revisión de la literatura mundial. Dossier. Rev Gerenc Políticas Salud 2009; 8:14-29.

11. World Health Organization. The World Health Report 2008. Primary health care: now more than ever. Geneva: World Health Organization; 2008.

12. Starfield B, Shi L, Macinko J. Contribution of primary care to health systems and health. Milbank Q 2005; 83:457-502.

13. Rovere M. Atención primaria de la salud en debate. Saúde Debate 2012; 36:327-42.

14. Paim J. Atenção primária à saúde: uma receita para todas as estações? Saúde Debate 2012; 36:343-7.

15. Testa M. Pensar em saúde. Porto Alegre: Editora Artes Médicas; 1992.
16. Tejerina-Silva H. Atención primaria de salud en Bolivia, Ecuador y Venezuela. ¿Transición hasta la atención primaria integral? In: Giovanella L, organizadora. Atención primaria de salud en Suramérica. Rio de Janeiro: Instituto Sul-Americano de Governo em Saúde; 2015. p. 111-51.

17. Levino A, Carvalho EF. Análise comparativa dos sistemas de saúde da tríplice fronteira: Brasil/Colômbia/Peru. Rev Panam Salud Pública 2011; 30:490-500.

18. Silveira AC, Machado CV, Matta GC. A atenção primária em saúde na agenda da Organização Pan-americana de Saúde nos anos 2000. Trab Educ Saúde 2014; 13:31-44.

19. Buss PM, Ferreira JR. Cooperação e integração regional em saúde na América do Sul: a contribuição da Unasul-Saúde. Ciênc Saúde Coletiva 2011; 16:2699-711.

20. Vargas I, Mogollon-Pérez AS, De Paepe P, Silva MRF, Unger JP, Vazquez ML. Barriers to healthcare coordination in market-based and decentralized public health systems: a qualitative study in healthcare networks of Colombia and Brazil. Health Policy Plan 2016; 31:736-48.

21. Conill EM, Giovanella L, Almeida PF. Listas de espera em sistemas públicos: da expansão da oferta para um acesso oportuno? Considerações a partir do Sistema Nacional de Saúde espanhol. Ciênc Saúde Coletiva 2011; 16:2783-94

22. Tejerina-Silva H, Soors W, De Paepe P, Santacruz EA, Closon MC, Unger JP. Reformas de gobiernos socialistas a las políticas de salud en Bolivia y Ecuador: el potencial subestimado de la Atención Primaria Integral de Salud para impactar los determinantes sociales en salud. Med Soc 2009; 4:273-82.

23. Unger J-P, De Paepe P, Ghilbert P, Soors W, Green A. Disintegrated care: the Achilles heel of international health policies in low and middle income countries. Int J Integr Care 2006; 6:e14.

24. Bresser-Pereira LC. Democracia, estado social e reforma gerencial. Revista de Administração de Empresas 2010; 50:112-6.

25. Fleury S, Faria M, Durán J, Sandoval H, Yanes P, Penchaszadeh V, et al. Right to health in Latin America: beyond universalization. Santiago: Comisión Económica para América Latina y el Caribe; 2013. (Series Financing for Development).

26. Ministerio del Poder Popular para la Salud; Organización Panamericana de Salud. Medicina integral comunitaria. Médicos y médicas para el pueblo. Caracas: Ministerio del Poder Popular para la Salud/Organización Panamericana de Salud; 2013. 
27. Vega-Romero R, Acosta-Ramírez N. La atención primaria en sistemas de salud basados em el aseguramiento: el caso de Chile, Colombia y Perú. In: Giovanella L, organizadora. Atención primaria de salud en Suramérica. Rio de Janeiro: Instituto Sul-Americano de Governo em Saúde; 2015. p. 195-254.

28. Lavinas L. América Latina: mínimos monetários em lugar da proteção social. Revista de Política Social e Desenvolvimento 2014; 8:18-26.

29. Tejada de Rivero DA. Lo que es la atención primaria de salud: algunas consideraciones a casi treinta y cinco años de Alma-Ata. Rev Peru Med Exp Salud Pública 2013; 30:283-7.
30. World Bank. World development indicators 2016. Washington DC: World Bank; 2016.

31. Organización Panamericana de la Salud. Indicadores y datos básicos: 2014. Washington DC: Organización Panamericana de la Salud; 2014.

32. Organización Panamericana de la Salud. Indicadores y datos básicos: 2015. Washington DC: Organización Panamericana de la Salud; 2015.

33. Giovanella L, organizadora. Atención primaria de salud en Suramérica. Rio de Janeiro: Instituto Sul-Americano de Governo em Saúde; 2015. 


\section{Abstract}

The article analyzes recent reforms in primary health care in the South American countries, discussing the scope and challenges for establishing comprehensive primary health care in the region's health systems. The data sources were case studies conducted in 12 countries, and the analytical lines were the strategic components in the design and implementation of primary health care: $\mathrm{na}$ tional policy approaches, characteristics of financing, organization and provision, and the workforce in primary health care. The crosscutting analysis from a comparative perspective provides an overview of primary health care in the region's countries and highlights convergences and asymmetries. A common trait is the recovery of the expanded definition of primary health care with family and community components, a territorial base, multidisciplinary team, incorporation of community health workers, and social participation. Implementation revealed heterogeneities in the advances and contradictions in the models. Insufficient supply of physicians, difficulties in provision and physician retention in remote and peripheral areas, as well as in primary health care itself, precarious employment relations, and absence of career plans are common problems, and there have been recent initiatives in government intervention to direct the workforce to the public system. Segmentation of the supply of primary health care converges with the segmentation of social protection in the various countries, through maintenance of social insurance or selective and targeted insurance or coverage by private health insurance, and persistent exclusion of populations from the right to health. The article argues that implementation of comprehensive primary health care is conditioned by the prevailing modalities of social protection in health.

Primary Health Care; Health Systems; Public Policy; Health Policy

\section{Resumen}

El artículo analiza el proceso reciente de reformas de la atención primaria a la salud en los países de Suramérica, discutiendo el alcance y los desafíos para la constitución de una atención primaria integral en los sistemas de salud de la región. Teniendo como fuentes de información estudios de caso realizados en los 12 países, toma, como ejes de análisis, componentes estratégicos de la concepción e implementación de la atención primaria a la salud: enfoques en las políticas nacionales, características de financiación, organización y prestación y la fuerza de trabajo en atención primaria a la salud. El análisis transversal desde una perspectiva comparada ofrece un panorama de la atención primaria a la salud en los países de la región $y$ destaca convergencias y asimetrías. Se observa, como denominador común, la recuperación de la concepción ampliada de atención primaria a la salud con componentes familiares y comunitarios, base territorial, equipo multidisciplinario, incorporación de agentes comunitarios de salud $y$ participación social. En la implementación, las heterogeneidades en los avances y contradicciones en los modelos se destacan. La insuficiente oferta de médicos, dificultades para la provisión y fijación en zonas remotas y periféricas, así como en la propia atención primaria de salud, precariedad de los vínculos y ausencia de carrera son problemas comunes, con iniciativas recientes de intervención estatal en el direccionamento de la fuerza de trabajo para el sistema público. La segmentación de la oferta de atención primaria a la salud converge con la segmentación de la protección social en salud en los diversos países, sea por el mantenimiento de los seguros sociales, de los seguros selectivos $y$ focalizados, por la cobertura proporcionada por seguros privados de salud o por el mantenimiento de poblaciones excluidas del derecho a la salud. Se argumenta que la implementación de la atención primaria integral está condicionada a las modalidades de protección social en salud vigentes.

Atención Primaria de Salud; Sistemas de Salud; Politica Pública; Política de Salud
Recebido em 07/Jul/2016

Versão final reapresentada em 25/Set/2016

Aprovado em 13/Out/2016 